\title{
Numerical Simulation on Fracturing Bond Mechanisms of Different Basalt FRP Bars
}

\author{
Arafa M. A. IBRAHIM11, Mohamed F. M. FAHMY² and Zhishen WU3 \\ ${ }^{1}$ Ph.D. Candidate, Dept. of Urban and Civil Engineering, Ibaraki University \\ (Nakanarusawa-cho, Hitachi-shi, Ibaraki 316-8511, Japan) \\ E-mail:arafamai2015@gmail.com \\ 2 Research fellow' International Institute for Urban Systems Engineering, Southeast University, Nanjing, 210096 \\ China; and Lecturer, Dept. of Civil Engineering, Faculty of Engineering, Assiut University, Assiut, 71516 Egypt. \\ E-mail: mfmf1976@yahoo.com \\ ${ }^{3}$ Member of JSCE, Professor, Dept. of Urban and Civil Engineering, Ibaraki University \\ (Nakanarusawa-cho, Hitachi-shi, Ibaraki 316-8511, Japan) \\ E-mail: zswu@mx.ibaraki.ac.jp
}

\begin{abstract}
This paper presents experimental results and numerical simulation of direct pull-out tests of basalt fiber reinforced polymer (BFRP) bars embedded in concrete. First, two patches of experimental pull-out tests are briefly descried. In the first experimental patch, the influence of surface texture configuration of BFRP bars on the bonding characteristics between BFRP bars and concrete is investigated through direct pull-out tests carried out on concrete cubes reinforced with BFRP bars. Pull-out test on ribbed steel reinforced concrete cube was also carried out for comparison. In the other experimental patch, pull-out tests were carried out on BFRP bars embedded inside pre-drilled holes into heavy concrete blocks. Through these pull-out tests, the efficiency of two different adhesive materials; namely: epoxy putty and polymer cement, and the effect of cross-section diameter of BFRP bars on the BFRP bar-concrete bond mechanism were investigated. Second, a finite element model (FEM) was employed to analyze the interfacial behavior between BFRP bars and the surrounding materials. Through the FEM, the influence of the tested parameters on the characteristics of local bond-slip models of BFRP bars was assessed by considering different material properties as well as different fracturing bond mechanisms. The experimental and numerical results showed that the bonding behavior of BFRP bars-reinforced concrete structures can be improved by treating the surface texture configurations of BFRP bars. In addition, the properties of the adhesive material between BFRP bars and concrete are key factors controlling the bond mechanism of strengthened concrete structures. Moreover, the proposed FEM was found to be capable of simulating the fracturing bond mechanism of BFRP bars.
\end{abstract}

Key Words: BFRP, bar, bond, finite element modelling, pull-out

\section{INTRODUCTION}

Recently, structural durability, lightweight requirement, and recoverability after earthquake events have been considered as main issues for safety and sustainability of reinforced concrete (RC) infrastructures ${ }^{1)}$. Corrosion of steel reinforcement is one of the principal causes of deterioration of concrete elements subjected to aggressive environment 2). As a result of steel corrosion, both bond and structural performances of RC members are deteriorated and billions of dollars are spent every year to repair the associated damages. Moreover, the elasto-plastic characteristics of steel reinforcement would cause difficulty in quickly recovering structural functions after an earthquake ${ }^{3)}$.

To solve the above mentioned problems and hence enhance the performance of RC structures and extend their lives, fiber reinforced polymer (FRP) composites have been widely used in reinforcing and strengthening concrete structures $4,5,6)$. FRP composites like glass FRP (GFRP), carbon FRP (CFRP), and aramid FRP (AFRP) are widely known as high strength, light weight, corrosion and fatigue resistance, ease of construction materials in comparison to the conventional steel materials. Additionally, FRP composites have elastic characteristics. Therefore, by adding FRP bars to RC structures, the resulted composition could ensure a stable post-yield stiffness, which in turn 
enhances the strength demand and post-earthquake recoverability of the bridges7). Basalt FRP (BFRP) is one of the latest FRP composites that has been developed within the last 20 years and has been proven to show advantageous characteristics in comparison to other composites. For instance, BFRP has a higher strength and modulus, a similar cost, and more chemical stability compared with E-glass FRP and a wider range of working temperatures and much lower cost than CFRP ${ }^{1,8)}$. Due to the above advantages, BFRP has already become an attractive alternative for replacing conventional construction materials and is expected to enhance structural safety and sustainability. However, the fundamental studies and the relevant applications are still limited due to the relatively recent development compared with other FRP composites.

During the last few decades, a wide range of experimental and numerical studies have been carried out to investigate the structural performance of RC structures reinforced or strengthened with FRP bars. The results of a major number of these studies have revealed that the bond between FRP bars and concrete governs the serviceability, ductility, and capacity of concrete structures. Test results of previous studies on the bond performance of the conventional FRP bars showed that the unique characteristics of every FRP material and the wide variety of fiber/resin interfaces made the bond behavior hard to be predicted apart from experimental investigations ${ }^{8,}$ 9). Proper assessment of the parameters that are commonly known to influence bond of FRP bars to concrete is crucial to understand how BFRP bars develop their bond strength. Particularly, it has been reported that bond is strongly dependent on the surface characteristics of the FRP bar and its treatment ${ }^{10)}$. Furthermore, with the fast spreading of finite element modeling (FEM) of RC structures, an accurate bond-slip modeling of BFRP bars is crucially needed to be predicted to successfully simulate the behavior of $\mathrm{RC}$ structures that contain BFRP bars.

The present study is a part of an ongoing large research program aiming at assessing the use of BFRP bars in reinforcing and strengthening concrete structures. This study presents the results of pull-out tests carried out on BFRP bars embedded in concrete and bonded with different adhesive materials. A nonlinear three dimensional (3D) FEM is developed to address the effect of different parameters on the bonding behavior of BFRP bars.

\section{EXPERIMENTAL PULL-OUT TESTS}

Two patches of experimental tests were carried out. In the first patch (group 1), the effect of surface texture configurations on the bonding characteristics between BFRP bars and concrete was investigated through direct pull-out tests. In the second patch (group 2 and group 3), pull-out tests on BFRP bars of different diameters embedded into vertical holes drilled in heavy concrete blocks and bonded to concrete using polymer cement and epoxy putty, respectively, were carried out.

\section{(1) Experimental tests of group 1}

Pull-out tests on 10-mm-diameter BFRP bars with four different surface conditions were carried out. Designation of these bar samples are B10-S, B10SH10, B10-SH5, and B10-DH10. Where surface of B10-S was characterized by very small indentations (i.e., factory produced and named in all parts of this study smooth BFRP bar) and the other bars' surfaces were created by helically wrapping single or double, 1-mm-thickness, BFRP strands to the smooth bar as follows: B10-SH10 and B10-SH5 are BFRP bars with surfaces created by helically wrapping single strand around the smooth BFRP bar with pitch of $10 \mathrm{~mm}$ and $5 \mathrm{~mm}$, respectively; and B10-DH10 is a BFRP bar with a surface created by helically wrapping double strand around the smooth BFRP bars with $10 \mathrm{~mm}$ pitch. Additionally, for comparison, the same pull-out test was carried out on 10-mm-diameter ribbed steel bar (S10). Details of the investigated surface conditions are shown in Fig.1 and main experimental parameters, including the mechanical material properties of both BFRP and steel bars used, are shown in Table 1.

Table 1. Main experimental parameters and results of group 1

\begin{tabular}{|cccccccc|}
\hline Specimen & Type & $\begin{array}{c}D \\
(\mathrm{~mm})\end{array}$ & Surface & $\begin{array}{c}E \\
(\mathrm{Gpa})\end{array}$ & $\begin{array}{c}f_{u} \\
(\mathrm{Mpa})\end{array}$ & $\begin{array}{c}P_{m} \\
(\mathrm{kN})\end{array}$ & $\begin{array}{c}f_{m} / f_{u} \\
(\%)\end{array}$ \\
\hline B10-S & BFRP & 9.8 & S & 48 & 1120 & 24.2 & 29 \\
B10-SH10 & BFRP & 9.8 & SH10 & 48 & 1120 & 31.3 & 37 \\
B10-SH5 & BFRP & 9.8 & SH5 & 48 & 1120 & 36.9 & 44 \\
B10-DH10 & BFRP & 9.8 & DH10 & 48 & 1120 & 37.1 & 43 \\
S10 & Steel & 9.7 & ribbed & 210 & 560 & 37.9 & 80 \\
\hline
\end{tabular}

Note: $D$ is the bar diameter; $E$ is the modulus of elasticity, $f_{u}$ is the ultimate tensile strength, $P_{m}$ is the maximum pull-out force, and $f_{m}$ is the maximum corresponding axial stress.

Cube molds with 100-mm-edge length were used to prepare the pull-out tests. BFRP and steel bars of 800-mm-total length, and 250-mm-end portions encased by steel pipes (refer as the loaded end in the subsequent sections), were concentrically positioned in the molds prior to concrete casting.

Concrete compressive strength of $35 \mathrm{MPa}$ was determined as the average of three values obtained from compressive tests carried out on standard concrete cylinders. 


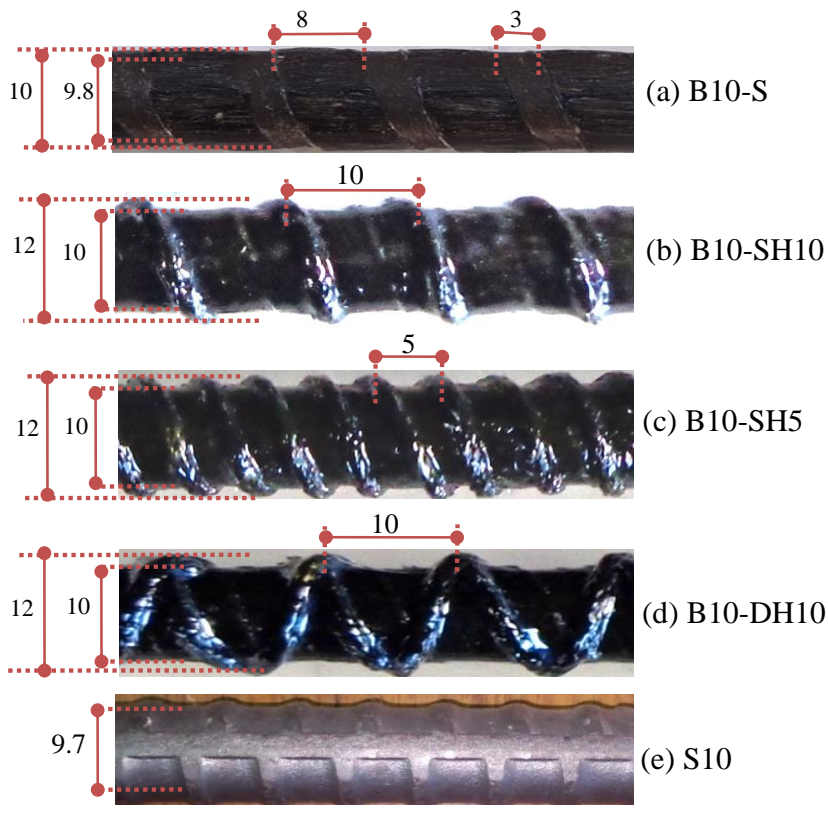

Fig.1 Surface texture configurations of BFRP and steel bars

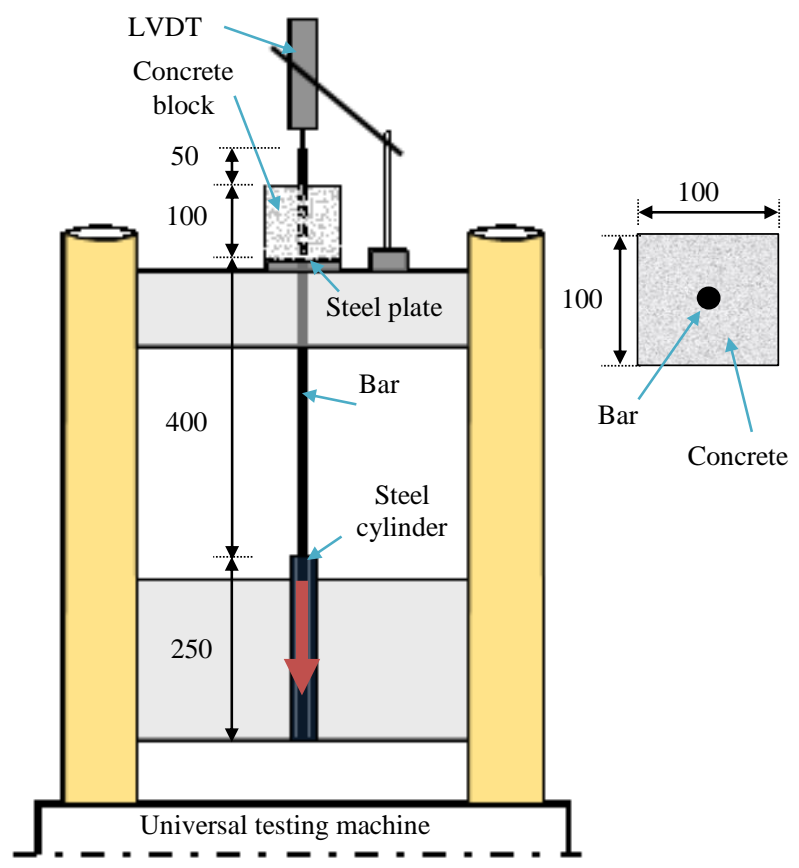

Fig.2 Schematic drawing of a typical test specimen of group 1

Pull-out arrangement is shown in Fig. 2. Test specimens were positioned in a universal testing machine having a load cell capacity of $500 \mathrm{kN}$. As shown in Fig. 2, direct tensile force is applied to the loaded end of the bar at a rate of $3 \mathrm{kN} / \mathrm{min}$., while the displacement was recorded using a linear variable displacement transducer (LVDT) attached to the free end of the bar. During the test, a data acquisition system was used to record the applied load and the displacement readings.

\section{(2) Experimental tests of groups 2 and 3}

Two groups (2 and 3), comprising three specimens each, of pull-out tests were carried out, where epoxy putty and polymer cement were used as filling material, respectively. The used epoxy putty had a tensile strength and modulus of elasticity of $49 \mathrm{MPa}$ and $3.45 \mathrm{GPa}$, respectively and the used polymer cement gave a compressive strength of 30 $\mathrm{MPa}$, after seven days. Through this test, the modes of failure, the maximum loads, and the degradation behavior after the peak load of strengthened concrete blocks using the two adhesive materials were compared in three different diameters of smooth BFRP bars; namely: 6, 10, and $12 \mathrm{~mm}$.

A set of concrete blocks were used to carry out the pull-out tests, where each concrete block had dimensions of $400 \mathrm{~mm}$ height, $300 \mathrm{~mm}$ width, and $1800 \mathrm{~mm}$ length. Normal strength concrete was used for all concrete blocks, and the average compressive strength of three tested cylinders was $30 \mathrm{MPa}$ after 28 days. After hardening of concrete, three holes of $30 \mathrm{~mm}$ diameter and $240 \mathrm{~mm}$ length at equal distances were drilled into each concrete block using an electrical hammer drill. After excavation, all holes were cleaned using compressed air and Ethanol. Moreover, for cases of polymer cement as adhesive material (group 3), the perimeter of holes was painted with Primer after ethanol and left for about one week before embedding the polymer cement and BFRP bars.

The BFRP bars were cut into $1000 \mathrm{~mm}$ long. Before embedding the BFRP bars inside the holes, one end of the bar sample was embedded in a steel cylinder (with $300 \mathrm{~mm}$ long). After words, an expansive grout (cement-based grout) was used to bond the BFRP bars to the steel cylinders. To apply the pull-out forces on the tested bars without any slippage between the bars and the steel cylinders during the tests, it was very necessary to anchor the loaded ends of the bars with sufficient length and by using a strong material. To do so, preliminary tensile tests were carried out on BFRP bars of 12mm-diameter anchored to $300 \mathrm{~mm}$ length inside steel cylinders by the same specified grout. Results of these tests showed sufficient bond between the bars, grout, and cylinders; that is no slippage was observed during the tests up to rupture of the bars. After hardening of the grout, a part of the free end of the considered BFRP bar was embedded in the hole and bonded with the epoxy putty or polymer cement. The pullout tests were performed using the setup shown in Fig. 3, where a hydraulic jack was used for pulling the BFRP bars and two displacement transducers (LVDTs) were used to measure the global displacements. 


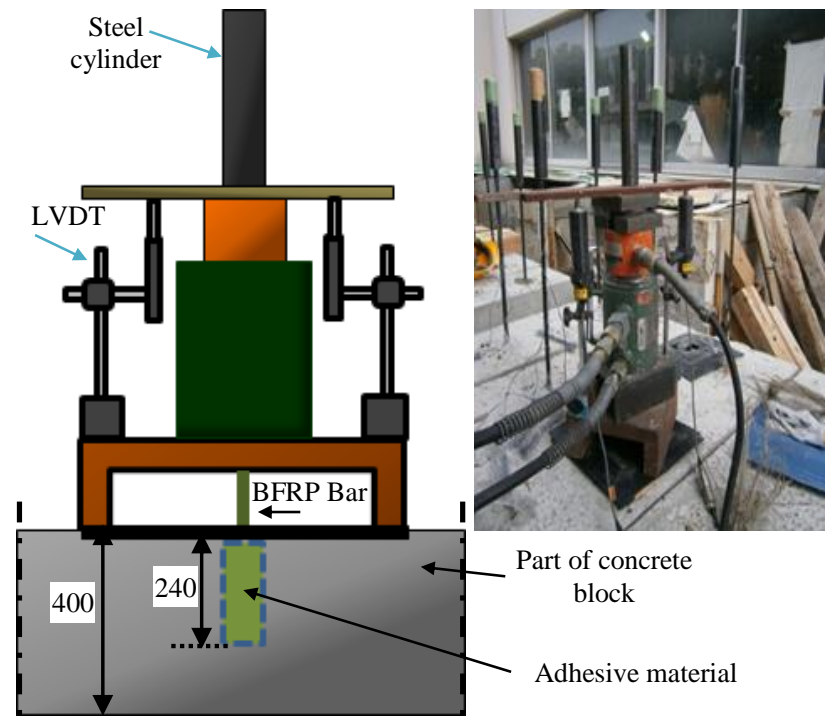

Fig.3 Schematic drawing of a typical specimen of groups 2 and 3

\section{FINITE ELEMENT MODELING}

The pull-out tests were modeled using ANSYS code version 1311). In addition to predict the response of the concrete blocks reinforced or strengthened with BFRP bars, the FEM was employed to give insight into the effect of the investigated parameters on the bond characteristics of BFRP bars with concrete. In order to achieve this objective, a regression analysis was performed to identify the bond-slip parameters for each specimen by fitting the pull-out force versus displacement recorded in the experimental tests. A 3D FEM for each group was constructed with dimensions similar to the experimental specimens as shown in Fig. 4. For specimens in group 1, only a quarter of the specimen was modeled considering two planes of symmetry. For the other two groups, a cylinder core with 300-mm-diameter was considered and again only a quarter of this core was modeled.

For specimens in group 1, concrete cracks as well as crushing at the loaded end of the pull-out specimens concentrated in a small cylindrical portion (i.e., with approximately 40 -mm-diameter) around the bars. Therefore, FE model for the specimens in this group consisted of: (1) outer solid concrete elements with elastic material properties, (2) inner solid concrete elements with nonlinear material properties for the inner square concrete core with 50-mm-length, (3) bar elements for BFRP and steel bars, (4) solid elastic steel elements for the steel plate (i.e., located between the frame of the testing machine and the concrete specimens), and (5) interface elements between the bars and nonlinear concrete elements.

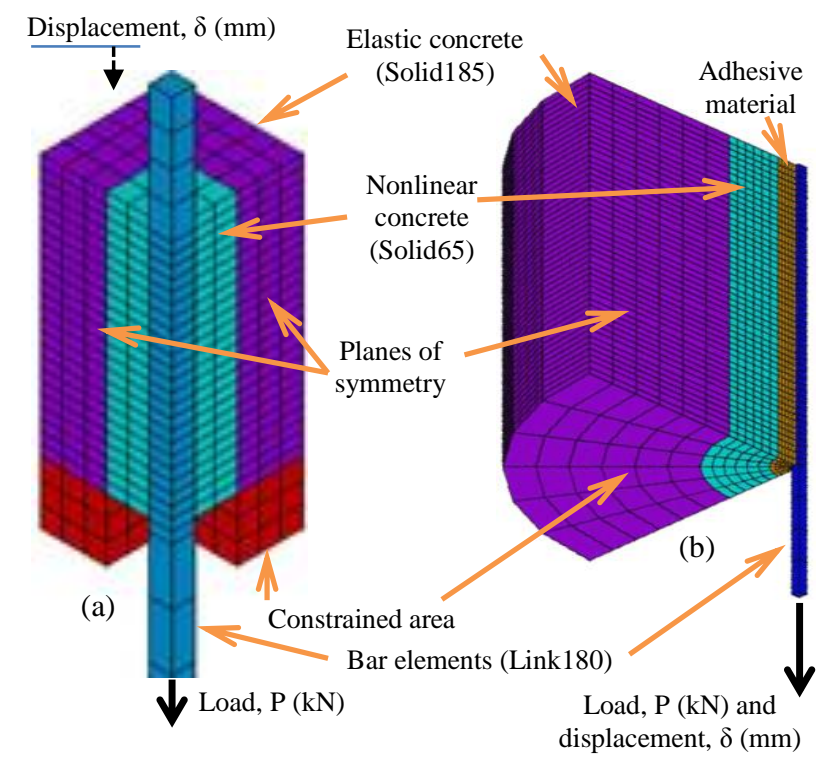

Fig.4 FEM of specimens in group a (a) and groups 2 and 3 (b)

During testing the specimens in the other groups (groups 2 and 3), small cracks appeared in a concrete layer with approximately 30-mm-thickness outside the adhesive material. Moreover, a very thin concrete was observed attaching to the pulled epoxy putty after the tests of specimens in group 3. Therefore, elements of specimens in groups 2 and 3 were also divided into five different elements: (1) outer solid elastic concrete elements outside internal nonlinear concrete elements, (2) internal solid nonlinear concrete elements with 50-mm-thickness around the adhesive material, (3) solid elements for the adhesive materials, (4) bar elements for BFRP bars, and (5) interface elements.

In the proposed FE models, element types, material models, and boundary conditions were carefully nominated and employed to simulate the performance of the tested specimens. Details of the FE strategy are as follows:

\section{(1) Element types}

From the element library of ANSYS code version 1311), four elements were nominated and employed to simulate the behavior of the pull-out specimens. 3D 8-node solid structural element (SOLID65) was used to model the model the inner nonlinear concrete portion at the pull-out regions and the polymer cement. SOLID65 is used for the 3-D modeling of solids with or without reinforcing bars. The solid is capable of cracking in tension and crushing in compression. In concrete applications, for example, the solid capability of the element may be used to model the concrete while the rebar capability is available for modeling reinforcement behavior. The element is defined by eight nodes having three degrees of freedom at each node: translations in the nodal $\mathrm{x}, \mathrm{y}$, and $\mathrm{z}$ directions and 
isotropic material properties. Up to three different rebar specifications may be defined. The most important aspect of this element is the treatment of nonlinear material properties. The concrete is capable of cracking, crushing, plastic deformation, and creep. The following assumptions should be considered when dealing with SOLID65 element: cracking is permitted in three orthogonal directions at each integration point; If cracking occurs at an integration point, the cracking is modeled through an adjustment of material properties which effectively treats the cracking as a "smeared band" of cracks, rather than discrete cracks; The concrete material is assumed to be initially isotropic; whenever the reinforcement capability of the element is used, the reinforcement is assumed to be "smeared" throughout the element; and in addition to cracking and crushing, the concrete may also undergo plasticity, with the Drucker-Prager failure surface being most commonly used. In this case, the plasticity is done before the cracking and crushing checks.

The outer concrete portion, the epoxy putty, and the steel plate were modeled as elastic materials using a 3D 8-Node structural element (SOLID185) which is defined by eight nodes having three degrees of freedom at each node: translations in the nodal $\mathrm{x}, \mathrm{y}$, and $\mathrm{z}$ directions and has an excellent ability to model elastic materials.

BFRP and steel bars were represented by 3D 2node structural bar elements (LINK180). It is noteworthy that this element has three degrees of freedom at each node (translations in the $\mathrm{x}, \mathrm{y}$, and $\mathrm{z}$ directions) and has capability of plastic deformations.

To simulate the fracturing bond mechanism, the spring element (COMBIN39) of zero length was used to connect the nodes of the two different materials located at the weakest interface plane, based on the observations from the experimental tests. For instance, the weakest planes of specimens in groups 1 and 3 were considered at the barconcrete and bar-polymer cement interfaces, respectively, while it was considered at the epoxy putty-concrete interface in specimens of group 2. By adopting generalized force-deflection curves, bondslip relationship of the different cases studied could be obtained, as it will be addressed in detail in the following sections. It is worth to mention here that the concurrent nodes between the two adjacent surfaces representing the weakest interface planes were coupled in both the transverse and lateral directions. Bond between other adjacent surfaces was assumed prefect (i.e., the nodes of the elements were coincided).

\section{(2) Material models}

To simulate the nonlinear plastic behavior of concrete and polymer cement, ANSYS requires input data for material properties as follows: (1) elastic modulus $(E c)$; (2) uniaxial compressive strength $\left(f_{c}^{\prime}\right)$; (3) uniaxial tensile strength (modulus of rupture, $f t$ ); (3) Poisson's ratio; shear transfer coefficient for open and closed cracks $\left(\beta_{t}\right.$ and $\left.\beta_{c}\right)$; and (4) compressive uniaxial stress-strain relationship for the concrete. In this study, the nonlinear plastic behavior of concrete in compression was defined using the well-known Hognestad model ${ }^{12)}$, Fig. 5.a, while the concrete tensile stress-strain response was modeled using the ACI model 13), Fig. 5.b. In both models, $f_{c}^{\prime}$ is the maximum concrete compressive strength and $\varepsilon_{\mathrm{co}}$ is the corresponding axial strain $=2 f_{c}^{\prime} / E_{c}$, and $f_{t}$ is the ultimate tensile strength $=0.62\left(f_{c}^{\prime}\right)^{0.5}$. The concrete poison's ratio was assumed equal to 0.2 .
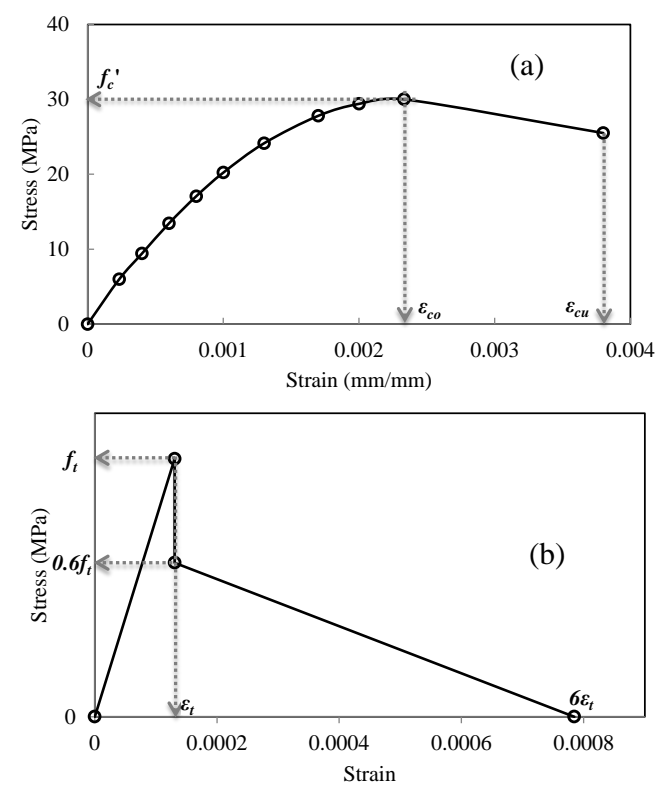

Fig.5 Concrete compressive stress-strain model (a) and tensile stress-strain model (b)

By using the uniaxial compressive strength $\left(f_{c}^{\prime}\right)$ and the uniaxial tensile strength $\left(f_{t}\right)$, ANSYS adopts the Willam and Warnke model ${ }^{14)}$ to define the failure of the concrete. In this model, both cracking and crushing failure modes are accounted for. A 3D failure surface for concrete is shown in Fig. 6. The most significant nonzero principal stresses are in the $\mathrm{X}$ and y directions, represented by $\sigma_{x p}$ and $\sigma_{y p}$, respectively. Three failure surfaces are shown as projections on the $\sigma_{x p}-\sigma_{y p}$ plane. The mode of failure is a function of the sign of $\sigma_{z p}$ (principal stress in the $\mathrm{Z}$ direction). For example, if $\sigma_{x p}$ and $\sigma_{y p}$ are both negative (compression) and $\sigma_{z p}$ is slightly positive (tensile), cracking would be predicted in a direction perpendicular to $\sigma_{z p}$. However, if $\sigma_{z p}$ is zero or 
slightly negative, the material is assumed to be crushed.

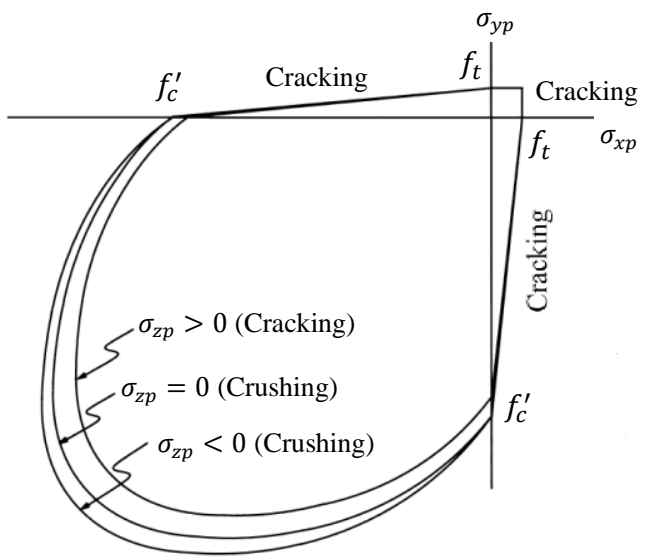

Fig.6 3D failure surface for concrete ${ }^{11)}$

After cracking, the tension stress of the concrete element is set to zero in the direction normal to the crack plane. The shear transfer coefficient $\beta_{t}$ for open cracks and $\beta_{c}$ for closed cracks determines the amount of shear transferred across the cracks. The value of these parameters range from 0.0 to 1.0, with 0.0 representing a smooth crack (complete loss of shear transfer) and 1.0 representing a rough crack (no loss of shear transfer). The value of $\beta_{t}$ used in many studies of RC structures, however, varied between 0.05 and $0.25^{18)}$. In this study, the values of $\beta_{t}$ and $\beta_{c}$ were assumed based on the work of Kachlakev et al. ${ }^{18)}$ as 0.2 and 0.9 , respectively.

The outer concrete of the specimens was simulated with elastic concrete material properties having the same modulus of elasticity and Poisson's ratio of the concrete of the column.

The nonlinear response of the steel bar was assumed to be bilinear elasto-plastic with a strainhardening ratio of $0.01^{18)}$, see Fig. 7.a. Steel Poisson's ratio was specified as 0.3. The FRP bars and epoxy putty were modeled as simplified uniaxial elastic material, Fig. 7.b. Finally, the rigid steel plate of loading were simulated with elastic steel material properties having a modulus of elasticity and Poisson's ratio of $200 \mathrm{GPa}$ and 0.3 , respectively.

\section{(3) Loading and boundary conditions}

Loading for all models was applied at the same locations of the experimental tests, where displacement-controlled load was applied to the loaded end of the tested bars while displacement was recorded at the free and loaded ends of the bars of specimens in group 1 and groups 2 and 3, respectively. Ultimately, symmetry boundary conditions were applied to the planes of symmetry. Details of the 3D FE models are shown in Fig. 4.
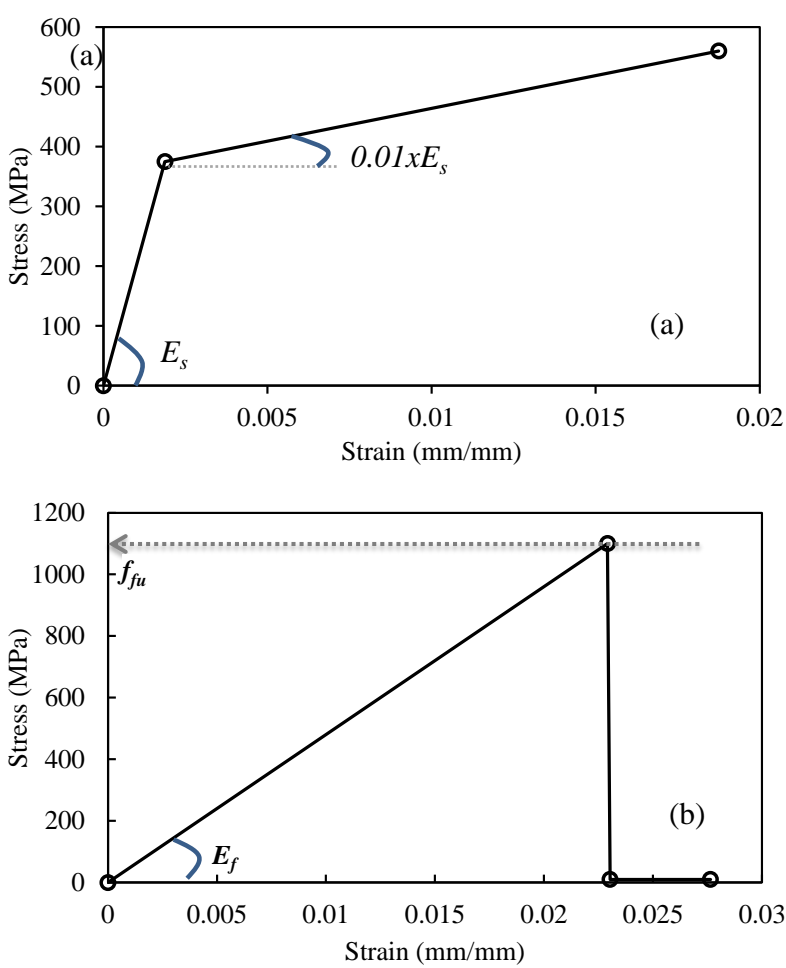

Fig.7 Bilinear stress-strain model for reinforcing steel (a), and elastic stress-strain model of FRP bars (b)

\section{(4) Bond-slip modeling}

To obtain the bond-slip responses for FRP bars in concrete, several experimental and analytical procedures have been reported in the last decades. The well-known BPE bond-slip model ${ }^{15)}$ for deformed steel bars was adopted by many researchers ${ }^{16,17)}$ to represent the local bond stressslip relationship of FRP bars. This model consisted of ascending curve up to the peak bond stress, then a plateau over which the peak bond stress is maintained followed by a descending branch with a steady-constant line at the end of the relationship. In this study, the BPE model was employed to investigate the effect of the considered variables on the bond behavior of BFRP bars as a reinforcing and strengthening tool for $\mathrm{RC}$ concrete structures.

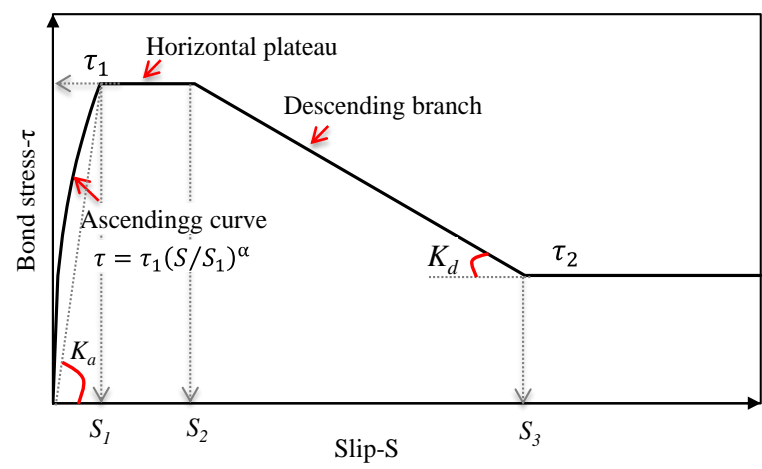

Fig.8 Local bond-slip model ${ }^{15)}$ 
As shown graphically in Fig. 8, six parameters may be used to describe the bond-slip law of steel and BFRP bars; namely: $\tau_{1}, S_{1}, S_{2}, \tau_{2}, S_{3}$, and $\alpha$, where $\tau_{l}$ is the peak bond stress, $S_{l}$ is the corresponding slip, $S_{2}$ is the slip at the end of the horizontal plateau zone, $\tau_{2}$ and $S_{3}$ are the residual bond stress and corresponding slip, respectively, and $\alpha$ is a parameter used to define the ascending branch (see Fig. 8). Other definitions for the ascending and descending branches are by using the ascending $\left(K_{a}\right)$ and descending $\left(K_{d}\right)$ stiffness, respectively.

The parameters of the bond-slip law were identified by altering their values until a suitable agreement between the experimental and numerical load-displacement curves were achieved.

\section{RESULTS AND DISCUSSIONS}

\section{(1) Specimens in group 1}

Table 1 presents the main data and results of the tested specimens in group 1, and Fig. 9 shows the load-displacement relations registered during the experimental pull-out tests together with those obtained from the numerical analysis. Where: $D$ is the diameter of steel or BFRP bar, $E$ is the elastic modulus, $f_{u}$ is the ultimate tensile strength, $p_{m}$ is the maximum load, and $f_{m}$ is the maximum corresponding axial stress.

The failure of all specimens was occurred at the bar-concrete interface. Minor cracks formed at the concrete surrounding the bar at early stage of loading. The cracks propagated and distributed to a wider zone with the increase in the applied load and at failure, a small amount of concrete has detached and pulled-out with the bar. The detached concrete in specimens with rough surface textures was clearer than that of specimens with smooth surface texture. Moreover, in specimens with rough surface textures, as the applied load became very close to the peak value, some ribs were broken and caused a decrease in the ascending stiffness up to the peak load, in which a plateau was formed followed by the debonding failure.

It is very clear from Fig. 9 that the loaddisplacement relation of all specimens consists of an ascending curve up to the peak load, then a stable zone over which the peak load is approximately maintained followed by a descending branch that is ended by a flouting curve.

By comparing the load-displacement relations of the tested specimens, it could be observed that all specimens shared almost the same stiffness up to approximately $45 \%$ of the maximum load of the specimen S10 (with deformed steel bar).
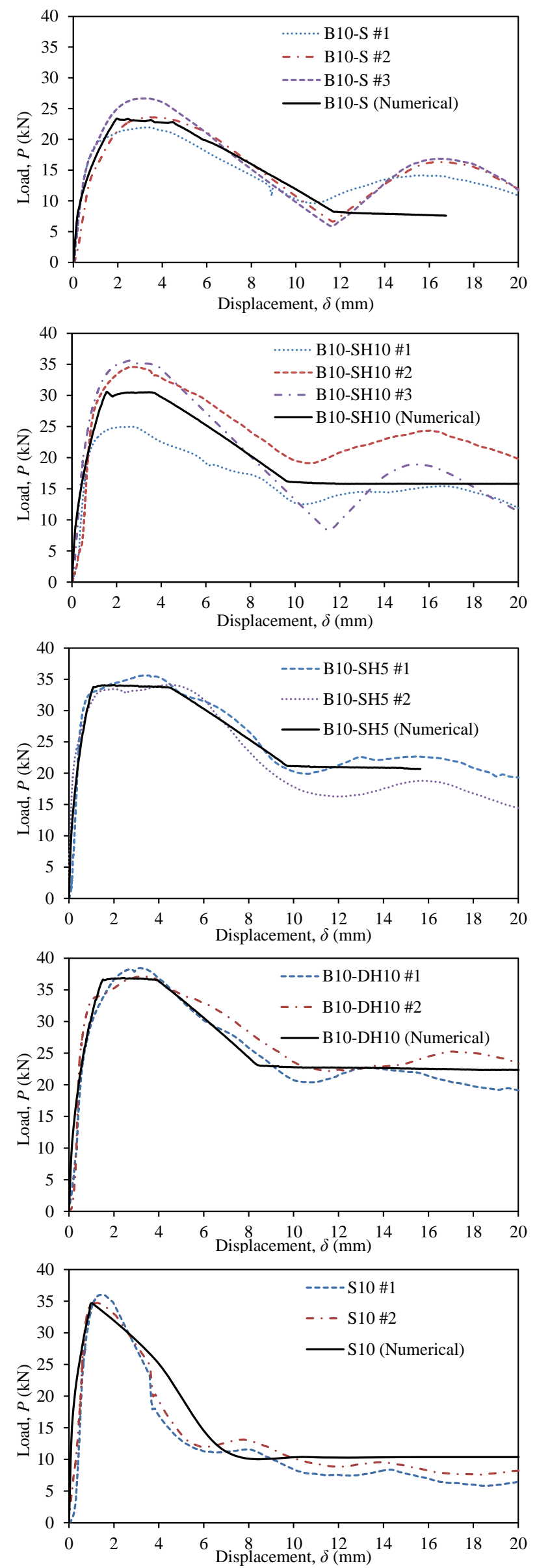

Fig.9 Experimental and numerical $P-\delta$ curves of group 1 
At this level, the stiffness of the specimen B10-S (with smooth BFRP bar) became smaller while the other specimens continued with similar stiffness as that of S10 up to approximately $85 \%$ of the maximum load.

The maximum attainable loads of specimens B10$\mathrm{S}, \mathrm{B} 10-\mathrm{SH} 10, \mathrm{~B} 10-\mathrm{SH} 5$, and $\mathrm{B} 10-\mathrm{DH} 10$ were approximately $62 \%, 82 \%, 96 \%$, and $97 \%$ of that of specimen S10, respectively. It is also clear that the degradation in the strength of the specimen B10-S after the peak load is more stable than that of other BFRP specimens with rough surface textures and the degradation of specimens with BFRP bars has a much stability than that of the specimen with deformed steel bar.

The values of the bond-slip parameters obtained from the inverse analysis using the FEM for each experimental curve are listed in Table 2. Moreover, a comparison between the obtained bond-slip curves of all specimens is shown in Fig. 10. It is clear from this figure that the proposed bond-slip law could be used successfully to simulate the global behavior of all tested specimens with various surface textures of BFRP bars. Furthermore, the main trim of the bondslip parameters, Table 2, agrees well with the experimental observations.

As it is evident in both Table 2 and Fig. 10, the bond strength $\left(\tau_{m}\right)$ and the ascending stiffness $\left(K_{a}\right)$ of the smooth BFRP bar (B10-S) was approximately $60 \%$ and $35 \%$ of those of the ribbed steel bar (S10), respectively. By adding a single spiral wounding with $10-\mathrm{mm}$-spacing to the surface of the smooth bar (B10-SH10), the values of $\tau_{m}$ and $K_{a}$ increased to $78 \%$ and $55 \%$ of those of the ribbed steel bar, respectively. While by adding a single spiral wounding with closer spacing (B10-SH5) or by adding double crossing wounding (B10-DH10), the average values of $\tau_{m}$ and $K_{a}$ became $94 \%$ and $90 \%$ of those of the ribbed steel bar, respectively. Additionally, the stability at the peak strength, that is expressed by the ratio $S_{2} / S_{1}$, and works as a ductility and fracture energy index for the bond mechanism of the BFRP bars had values greater than that of the steel bar. Similarly, the slope of the descending branch of the bond strength-slip curve of all specimens with BFRP bars was much less than that of the steel bar, and this slope increased when adding roughening to the bar surface.

Table 2. Bond-slip model parameters of specimens in group 1

\begin{tabular}{|ccccccc|}
\hline Specimen & $\begin{array}{c}\tau_{m} \\
(\mathrm{Mpa})\end{array}$ & $\begin{array}{c}K_{a} \\
\left(\mathrm{~N} / \mathrm{mm}^{3}\right)\end{array}$ & $S_{2} / S_{1}$ & $\begin{array}{c}K_{d} \\
\left(\mathrm{~N} / \mathrm{mm}^{3}\right)\end{array}$ & $\tau_{2} / \tau_{1}$ & $\alpha$ \\
\hline B10-S & 7.2 & 6.5 & 2.0 & 0.60 & 0.50 & 0.5 \\
B10-SH10 & 10.9 & 6.4 & 1.7 & 0.74 & 0.55 & 0.5 \\
B10-SH5 & 11.2 & 12.4 & 4.0 & 0.78 & 0.50 & 0.5 \\
B10-DH10 & 12.2 & 5.5 & 1.6 & 0.85 & 0.5 & 0.5 \\
S10 & 12.1 & 12.1 & 2.0 & 2.05 & 0.3 & 0.4 \\
\hline
\end{tabular}

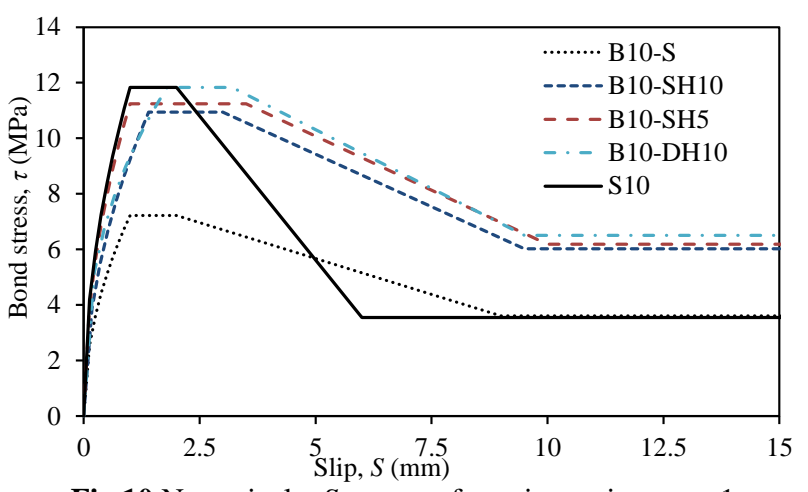

Fig.10 Numerical $\tau$-S curves of specimens in group 1

\section{(2) Specimens in groups 2 and 3}

Table 3 presents the experimental parameters and results of the specimens in groups 2 and 3.

Table 3. Main experimental parameters of groups 2 and 3

\begin{tabular}{|cccccccc|}
\hline Specimen & Adhesive & $\begin{array}{c}D \\
(\mathrm{~mm})\end{array}$ & $\begin{array}{c}E \\
(\mathrm{Gpa})\end{array}$ & $\begin{array}{c}f_{u} \\
(\mathrm{Mpa})\end{array}$ & $\begin{array}{c}P_{m} \\
(\mathrm{kN})\end{array}$ & $\begin{array}{c}f_{m} / f_{u} \\
(\%)\end{array}$ & $\begin{array}{c}\text { Failure } \\
\text { mode }\end{array}$ \\
\hline E-B6 & Epoxy & 5.9 & 47 & 1030 & 25.6 & 95 & $\mathrm{R}$ \\
E-B10 & putty & 9.8 & 48 & 1113 & 73.1 & 88 & R\&EC \\
E-B12 & & 11.7 & 49 & 1115 & 92.6 & 74 & EC \\
P-B6 & Polymer & 5.9 & 47 & 1030 & 14.3 & 56 & BP \\
P-B10 & cement & 9.8 & 48 & 1113 & 22.9 & 28 & BP \\
P-B12 & & 11.7 & 49 & 1115 & 29.1 & 24 & BP \\
\hline
\end{tabular}

Note: BP is bond failure at bar-cement past interface, EC is bond failure at putty-concrete interface, $\mathrm{R}$ is rupture failure of BFRP bar, and R-EC is a combination of partial rupture and bond failure.

During the experimental tests, full rupture of the BFRP bars with the smallest diameter and bonded using epoxy putty (E-B6) led to a sudden drop of the axial load. With increasing the bar diameter to 10 $\mathrm{mm}$ (E-B10), the epoxy putty-concrete interface became weaker, in which the failure mode of this sample was characterized by partial rupture of BFRP bar followed by failure of the putty-concrete interface. With additional increase in the bar diameter (E-B12), the failure mode was characterized by a complete breakage of the bond surface between concrete and the epoxy putty, which resulted in a brittle pull-out failure. It was also observed that a thin layer of the concrete attached to the epoxy putty was crushed and pulledout with the putty. On the other hand, the failure mode of the pull-out tests using polymer cement as a filling material (group 3) was characterized by cracks in the cement mortar and breakage at the BFRP bar-mortar interface. Experimental and numerical load-displacement relations of the specimens in groups $\mathrm{E}$ and $\mathrm{P}$ are shown in Figs. 11 and $\mathbf{1 2}$, respectively. 

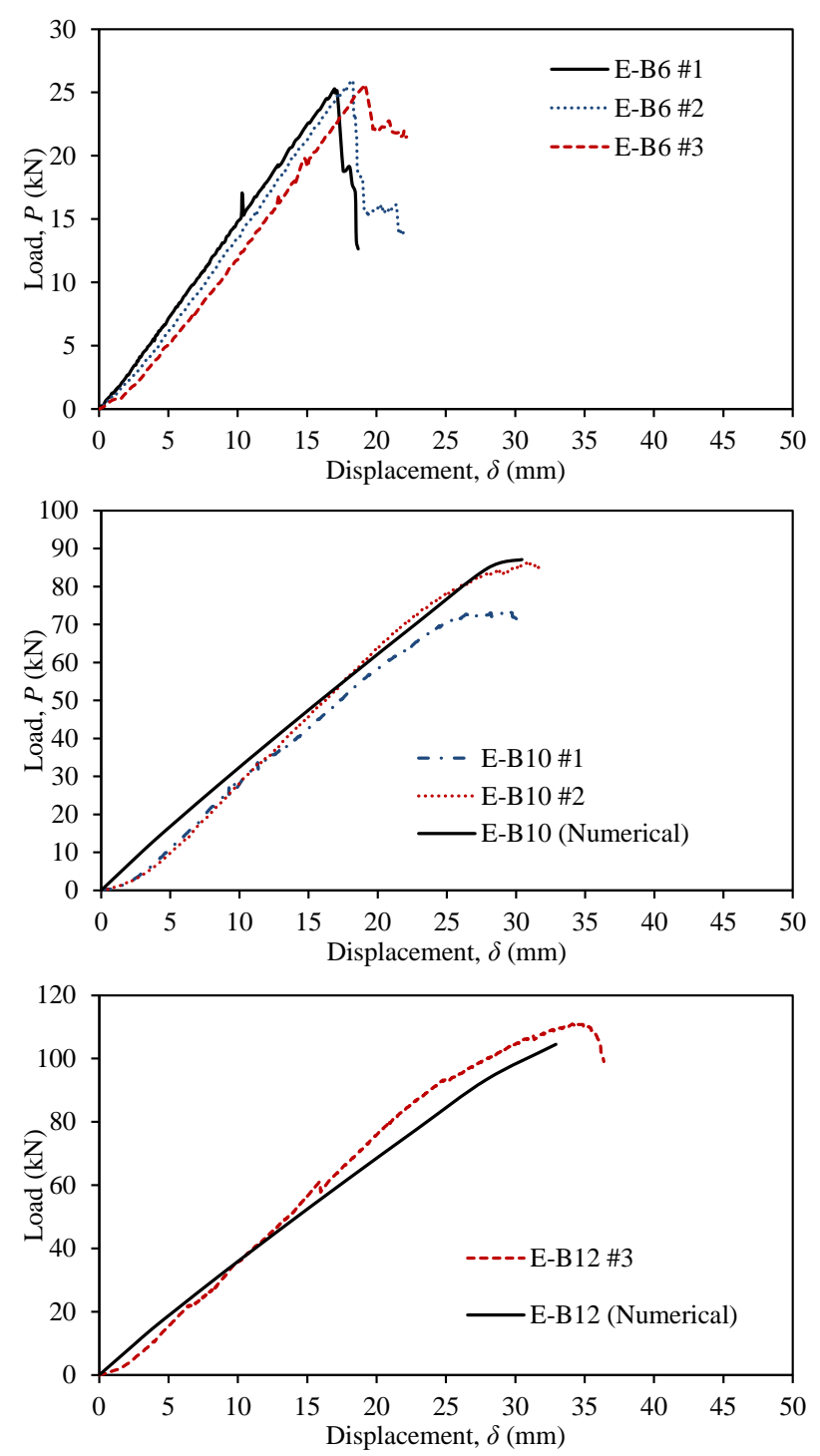

Fig.11 Experimental and numerical $P-\delta$ curves of group 2

Another main aspect of this test is that, as shown in Fig. 13, the ultimate loads for specimens with polymer cement as a filling material were 45 to $70 \%$ less than their counterparts with epoxy putty. Moreover, a very stable and gradual decrease in the strength after reaching the ultimate load was clearly observed in specimens with polymer cement compared with a sudden decrease in the specimens with epoxy putty.

Table 4. Parameters of $\tau$-S models of groups 2 and 3

\begin{tabular}{|ccccccc|}
\hline Specimen & $\begin{array}{c}\tau_{m} \\
(\mathrm{Mpa})\end{array}$ & $\begin{array}{c}K_{a} \\
\left(\mathrm{~N} / \mathrm{mm}^{3}\right)\end{array}$ & $r$ & $\begin{array}{c}K_{d} \\
\left(\mathrm{~N} / \mathrm{mm}^{3}\right)\end{array}$ & $\tau_{r} / \tau_{m}$ & $\alpha$ \\
\hline E-B10 & 11.8 & 1.2 & 1.2 & ------ & ------ & 0.9 \\
E-B12 & 10.5 & 0.9 & 1.2 & ------ & ------ & 0.9 \\
P-B6 & 2.8 & 0.7 & 1.2 & 0.07 & 0.5 & 0.7 \\
P-B10 & 3.0 & 0.6 & 1.2 & 0.13 & 0.3 & 0.7 \\
P-B12 & 2.7 & 0.4 & 1.2 & 0.09 & 0.6 & 0.7 \\
\hline
\end{tabular}

The results of the experimental tests was confirmed by that of the numerical modeling, as presented in Table 4 and Figs. 11, 12, and 13. The values of the bond strengths and ascending stiffness of BFRP bars bonded by polymer cement (group 3) was much less than the corresponding values of BFRP bars bonded by epoxy putty (group 2). Furthermore, the post-peak behavior of the bondslip curves of specimens in group 3 was characterized by a very stable descending stiffness, while it was characterized by a sudden drop in the case of specimens in group 2 .
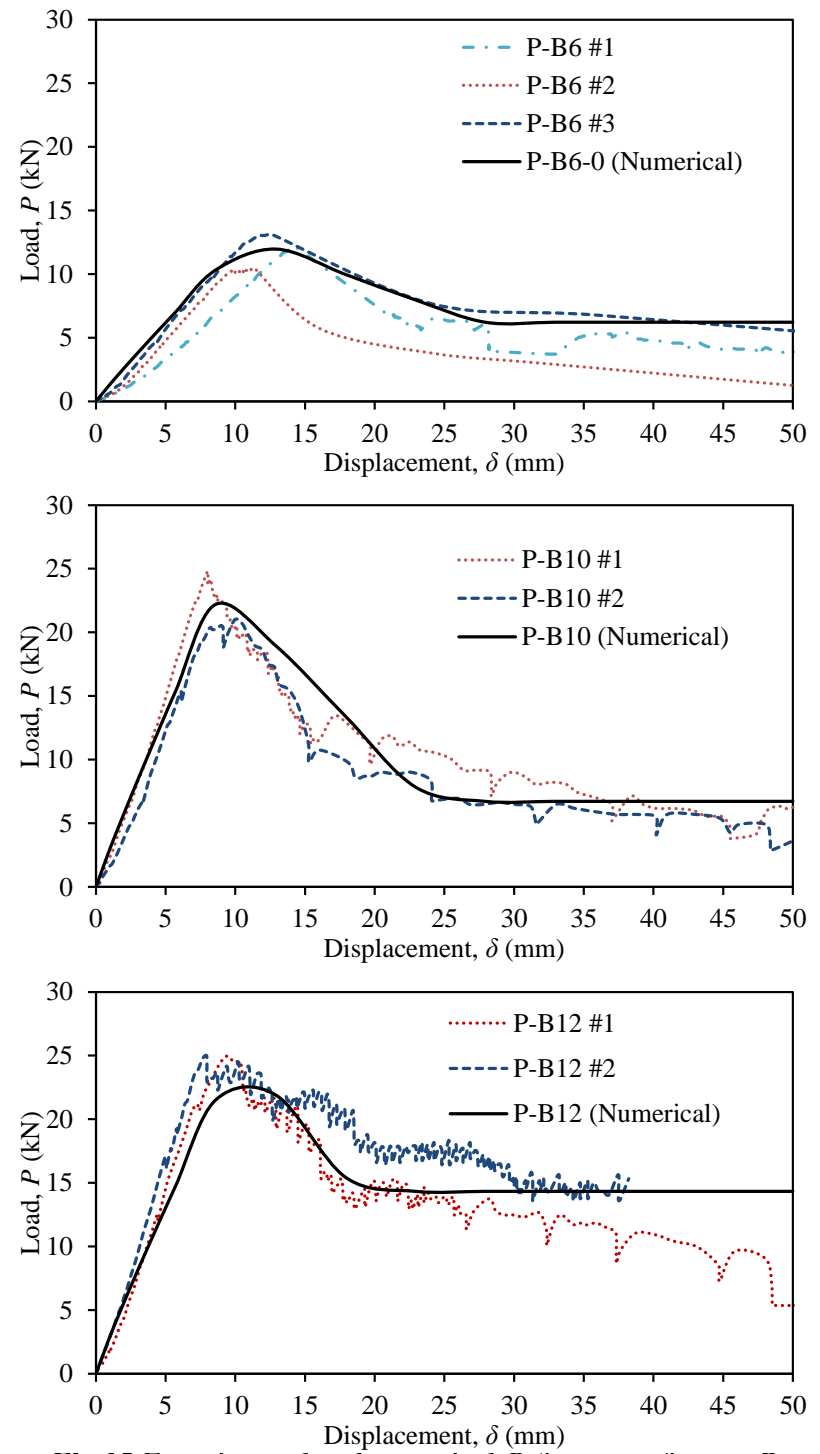

Fig.12 Experimental and numerical $P-\delta$ curves of group $\mathrm{P}$

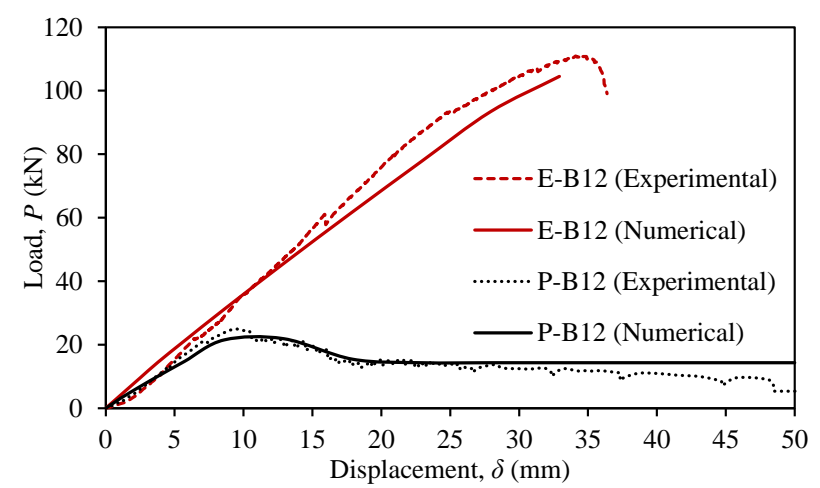

Fig.13 Comparison between $P-\delta$ curves of groups $\mathrm{E}$ and $\mathrm{P}$ 
Although the experimental results showed that as the diameter of BFRP bar increases the maximum load strength increases, the numerical modeling show that by changing the diameter of BFRP bar, only slight differences in the bond strength were resulted.

\section{CONCLUSION}

The experimental investigations as well as the numerical analysis of this study showed that the configuration of surface textures of BFRP bars has a significant effect on the ascending stiffness, peak bond strength, stability at the peak strength, and the descending branch of the bond-slip behavior of BFRP bars. By enhancing the surface of BFRP bars, the bond strength increased significantly and became comparable to that of deformed steel bars and the decending curve becames sharper than that of the smooth bars. The mechanical properties of the adhesive material that used to bond BFRP bars to concrete control the bonding mechanism of BFRP bars. Bonding BFRP bars to concrete by epoxy putty is characterized by high bond strength followed by rupture of BFRP bar or brittle failure at the epoxy-concrete interface. By using polymer cement, the behavior was characterized by low peak strength followed by ductile bond failure at the barcement interface. On the other hand, by employing a 3-D FE modeling, it was possible to identify the bonding behavior of BFRP bar to concrete.

\section{REFERENCES}

1) Wu, Z., Wang, X., and Wu, G. : Advancement of structural safety and sustainability with Basalt Fiber Reinforced Polymers, Proc. of 6th International Conference on FRP Composites in Civil Engineering, CICE, Rome, Italy, 2012.

2) Al-Hammoud, R., Soudki, K., and Topper, T.H. : Bond analysis of corroded reinforced concrete beams under monotonic and fatigue loads, Cement and Concrete Composites, Vol. 32, Pt. 3, pp. 194-203, 2010.

3) Wu, Z., Fahmy, M.F.M., and Wu, G. : Safety enhancement of urban structures with structural recoverability and controllability, $J$. earthquake and tsunami, Vol. 3, Pt. 3, pp. 143-174, 2009.
4) Seible, F. ,Priestley, M.J.N., and Innamorato, G.A. D. : Seismic retrofit of RC columns with continuous carbon fiber jackets, J Compos Constr, Vol. 1, Pt 2, pp. 52-62, 1997.

5) Lacobucci, R.D., Sheikh, S.A., and Bayrak, O. : Retrofit of square concrete columns with carbon fiber-reinforced polymer for seismic resistance, ACI Struct J, Vol. 100, Pt 6, pp. 785-794, 2003.

6) Bournas, D.A., and Triantafillou, T.C. : Flexural Strengthening of Reinforced Concrete Columns with NearSurface-Mounted FRP or Stainless Steel, ACI Struct J, Vol. 106, Pt. 4, pp. 495-505, 2009.

7) Fahmy, M. F. M., Wu, Z., Wu, G. , and Sun, Z. : Post-yield stiffnesses and residual deformations of RC bridge columns reinforced with ordinary rebars and steel fiber composite bars, J. Eng. Struct., Vol. 32, Pt. 9, pp. 29692983, 2010.

8) El Refai, A., Ammar, M., and Masmoudi, R. : Bond Performance of Basalt Fiber-Reinforced Polymer Bars to Concrete, J. Compos. Constr., Vol. 19, Pt. 3, 04014050 , 2015.

9) Aiello, M.A., Leone, M. and Pecce, M. : Bond Performances of FRP RebarsReinforced Concrete, J. Mat. . Civil Eng., Vol. 19, Pt. 3, pp. 205- 213, 2007.

10) Baena, M., Torres, L., Turon, A. and Barris, C. : Experimental study of bond behaviour between concrete and FRP bars using a pull-out test, $J$ Composites: Part B, Vol. 40, pp. 784-797, 2009.

11) ANSYS User's Mannual, Release 13.0. ANSYS, INC., Canonsburg, Pennsylvania, 2010.

12) Hognestad, E, Hanson, N.W., McHenry, D. : Concrete Stress Distribution in Ultimate Strength Design, ACI Struct J ,Vol. 52, Pt. 4, pp. 455-479, 1955.

13) ACI 318 (2011). Building code requirement for structural concrete (ACI 318-11) and commentary. American Concrete Institute, Farmington Hills, USA.

14) William, K.J., Warnke, E.D. : Constitutive Model for the Triaxial Behaviour of Concrete, Proc. of the International Association for Bridge and Structural Engineering, ISMES, Bergamo, Italy, 19,174, 1975.

15) Eligehausen, R., Popov, E.P. and Bertero, V.V.: Local bond stress-slip relationships of deformed bars under generalized excitations, Rep. No. 83/23, Earthquake Engineering Research Center (EERC), University of California, Berkeley, California, 1983.

16) Cosenza, E., Manfredi, G. and Realfonzo, R. : Behaviour and modeling of bond of FRP rebars to concrete, J. Comp. Construct., Vol. 1, Pt. 2, pp. 40-51, 1997.

17) Rossetti, A.V., Galeota, D. ,and Giammatteo, M.M. : Local bond stress-slip relationships of glass fibre reinforced plastic bars embedded in concrete, J Mater Struct, Vol. 28, Pt 180, pp. 340-344, 1995.

18) Kachlakev, D., Miller, T., Yim, S.: Finite element modeling of reinforced concrete structures strengthened with FRP laminates. Oregon Dept. of Transp., USA, Res. Group, Final Report SPR, 316, 2001.

(Received June 23, 2015) 